\title{
Preliminary Investigation on the Effect of Lactobacillus and Epidermal Growth Factor on Tight Junction Proteins in Experimental Clostridium difficile Infection
}

\author{
Sukhminderjit Kaur1, Chetana Vaishnavi1 ${ }^{*}$, Pallab Ray², Malkit Singh², Rakesh Kochhar ${ }^{1}$ \\ ${ }^{1}$ Departments of Gastroenterology, Postgraduate Institute of Medical Education and Research, \\ Chandigarh, India \\ ${ }^{2}$ Medical Microbiology, Postgraduate Institute of Medical Education and Research, Chandigarh, India \\ Email: ${ }^{*}$ cvaishnavi@rediffmail.com
}

Received 7 April 2014; revised 7 May 2014; accepted 17 May 2014

Copyright $@ 2014$ by authors and Scientific Research Publishing Inc.

This work is licensed under the Creative Commons Attribution International License (CC BY). http://creativecommons.org/licenses/by/4.0/

(c) (i) Open Access

\section{Abstract}

Clostridium difficile associated disease (CDAD) is the most common hospital acquired infection, due to exposure to various drugs. $C$. difficile toxins influence barrier function in intestinal epithelium. Biotherapeutic approaches, employing probiotic and epidermal growth factor (EGF) could help in barrier protein protection and aid in CDAD management. A preliminary investigation on the effect of Lactobacillus acidophilus and EGF on tight junction proteins in experimentally induced $C$. difficile infection was done. BALB/mice were divided into 5 groups. Group 1 was comprised of healthy controls, whereas animals in Groups 2 - 5 were sub-divided into 3 subgroups (a, b and c) each. Animals in Groups 2 - 5 received $C$. difficile inoculum either on day 1 (Group 2) or after pretreatment with ampicillin (Group 3), cyclosporine (Group 4) or lansoprazole (Group 5). Additionally animals in subgroups "b" and "c" also received L. acidophilus and EGF inocula respectively after $C$. difficile challenge. All animals were investigated for the presence of tight junction proteins (occludin, $\alpha$-actinin and zonula occludens) in their colonic segments. Data were analyzed using the SPSS version 10 software. These three proteins were present in significantly less $(P<$ $0.05)$ number of animals in the drug receiving animals, whereas they were found in significantly more $(P<0.05)$ number of animals receiving $L$. acidophilus and EGF after challenge with ampicillin, cyclosporine and lansoprazole, suggesting their role in protecting intestinal barrier function.

\section{Keywords}

Antibiotic, C. difficile, Epidermal Growth Factor, Immunosuppressive Drug, Probiotic,

*Corresponding author.

How to cite this paper: Kaur, S., Vaishnavi, C., Ray, P., Singh, M. and Kochhar, R. (2014) Preliminary Investigation on the Effect of Lactobacillus and Epidermal Growth Factor on Tight Junction Proteins in Experimental Clostridium difficile Infection. Advances in Microbiology, 4, 425-435. http://dx.doi.org/10.4236/aim.2014.48047 


\section{Introduction}

Clostridium difficile, a Gram positive, anaerobic, spore forming bacterium is the main etiologic agent of nosocomial diarrhea in industrialized countries [1] resulting in an increase in hospital stay, with high healthcare and economic repercussions. $C$. difficile associated disease (CDAD) ranges from asymptomatic carrier state at one end of the spectrum to fulminant colitis at the other end [2]. While antibiotic exposure is the most important risk factor for C. difficile infection, other medications may also trigger CDAD in hospitalized patients [3] as they receive several drugs like antibiotics, immunosuppressives and anti-ulcer medication simultaneously for their underlying diseases. These drugs debilitate the patients and disrupt their normal protective barrier predisposing the patients to nosocomial infections like CDAD.

C. difficile is the most commonly identified cause of antibiotic-associated diarrhea, accounting for $15 \%$ to $25 \%$ of the cases [4]. The pathogenecity of CDAD is attributed to two potent exotoxins, toxin A and toxin B, produced by the organism [5] leading to intestinal mucosal necrosis and inflammation. The intestinal epithelial cells are formed by a single layer of epithelial cells separating the intestinal lumen from the underlying lamina propria. The space between these cells is sealed by tight junctions, which regulate the permeability of the intestinal barrier. Numerous proteins have been identified in this region [6]. C. difficile toxins have been documented to influence intestinal barrier function [7] by opening the tight junctions. Thus tight junctions play an important regulatory role in the intestinal barrier function.

Probiotics are living organisms upon which ingestion in certain numbers exert health benefits beyond inherent basic nutrition. Presence of probiotic strains lead to an increase in tight junction proteins at the cell boundaries and can also prevent or reverse the adverse effects of pathogens [6]. Similarly, epidermal growth factor (EGF) is a potent mitogenic peptide that reduces bacterial colonization and heals gastric ulcers. EGF regulates the preservation of barrier function and integrity of healthy colonic mucosa [8].

The present work was planned to study the protective effects of Lactobacillus acidophilus and EGF on tight junction proteins in experimental C. difficile infection after challenging the animals with antibiotic or immunosuppressive drug or proton pump inhibitor (PPI). The study was conducted on BALB/c mice because of the several advantages associated with it, inclusive of the fact that they mimic the C. difficile infection occurring in human beings.

\section{Methods}

The study was approved by the Institute Research Ethics Committee and Institutional Animal Ethics Committee. The investigations were conducted on four to six week old adult male BALB/mice $(\mathrm{n}=78)$ weighing approximately $25 \mathrm{~g}$ each. The animals in the study were divided into 5 groups. Group 1 comprised of healthy mice ( $\mathrm{n}=$ 6) that were not given any inoculum and served as control to all other groups. Animals in Groups $2-5$ ( $n=18$ each) were subdivided into 3 subgroups $\mathrm{a}, \mathrm{b}$ and $\mathrm{c}(\mathrm{n}=6$ each). They received $C$. difficile inoculum either on day 1 (Group 2) or after pretreatment with ampicillin (Group 3), cyclosporine (Group 4) or lansoprazole (Group 5). Apart from this, animals in subgroups "b" and "c" in Groups 2 - 5 also received Lactobacillus acidophilus and EGF inocula respectively for one week after $C$. difficile inoculation. The experimental design, the day of administration of various inocula and the day of sacrifice of animals are given in Table 1.

\subsection{Preparation and Administration of Various Inocula}

The preparation of various inocula was essentially the same as described elsewhere [9]. All inocula were administered orogastrically. Standard strain of C. difficile (W1194, ATCC 43594) positive for both toxins A and B (kindly provided by Dr. M. Delmee, Belgium) was given at a dose of $10^{8} \mathrm{CFU} / \mathrm{ml}$. Ampicillin inoculum was administered to animals in Group 3 (3a, 3b and 3c) in two divided doses (66 mg/kg body weight) for one week before challenging the animals with $C$. difficile. Cyclosporine was administered orogastrically to animals in Group 4 (4a, 4b and 4c) in two divided doses (10 mg/kg of body weight) for one week before C. difficile inoculation. Lansoprazole was administered orogastrically at a dose of $0.5 \mathrm{mg} / \mathrm{kg}$ body weight as a single dose daily 
Table 1. Experimental design, day of administration of various inocula and day of sacrifice.

\begin{tabular}{|c|c|c|c|c|c|c|c|c|c|c|c|c|c|}
\hline Group & Group 1 & & Group 2 & & & Group 3 & & & Group 4 & & & Group 5 & \\
\hline Sub-groups & 1 & $2 a$ & $2 b$ & $2 c$ & 3a & $3 b$ & $3 c$ & $4 a$ & $4 \mathrm{~b}$ & $4 c$ & $5 a$ & $5 b$ & $5 c$ \\
\hline & Control & CD & $\mathrm{CD}+\mathrm{PB}$ & $\begin{array}{l}\text { CD + } \\
\text { EGF }\end{array}$ & $\mathrm{AB}+\mathrm{CD}$ & $\begin{array}{c}\mathrm{AB}+ \\
\mathrm{CD}+\mathrm{PB}\end{array}$ & $\begin{array}{l}\mathrm{AB}+ \\
\mathrm{CD}+ \\
\mathrm{EGF}\end{array}$ & $\mathrm{CY}+\mathrm{CD}$ & $\begin{array}{c}C Y+ \\
C D+P B\end{array}$ & $\begin{array}{l}\text { CY + } \\
\text { CD + } \\
\text { EGF }\end{array}$ & $\begin{array}{c}\text { PPI + } \\
\text { CD }\end{array}$ & $\begin{array}{c}\mathrm{PPI}+ \\
\mathrm{CD}+ \\
\mathrm{PB}\end{array}$ & $\begin{array}{l}\text { PPI + } \\
\text { CD + } \\
\text { EGF }\end{array}$ \\
\hline Ampicillin & - & - & - & - & $\begin{array}{l}\text { day } \\
1-7\end{array}$ & $\begin{array}{l}\text { day } \\
1-7\end{array}$ & $\begin{array}{l}\text { day } \\
1-7\end{array}$ & - & - & - & - & - & - \\
\hline Cyclosporine & - & - & - & - & - & - & - & $\begin{array}{l}\text { day } \\
1-7\end{array}$ & $\begin{array}{l}\text { day } \\
1-7\end{array}$ & $\begin{array}{l}\text { day } \\
1-7\end{array}$ & - & - & - \\
\hline Lansoprazole & - & - & - & - & - & - & - & - & - & - & $\begin{array}{c}\text { day } \\
1-14\end{array}$ & $\begin{array}{c}\text { day } \\
1-14\end{array}$ & $\begin{array}{c}\text { day } \\
1-14\end{array}$ \\
\hline C. difficile & - & day 1 & day 1 & day 1 & day 8 & day 8 & day 8 & day 8 & day 8 & day 8 & day 15 & day 15 & day 15 \\
\hline L. acidophilus & - & - & $\begin{array}{l}\text { day } \\
2-7\end{array}$ & - & - & $\begin{array}{c}\text { day } \\
9-14\end{array}$ & - & - & $\begin{array}{c}\text { day } \\
9-14\end{array}$ & - & - & $\begin{array}{c}\text { day } \\
16-21\end{array}$ & - \\
\hline EGF & - & - & - & $\begin{array}{l}\text { day } \\
2-7\end{array}$ & - & - & $\begin{array}{c}\text { day } \\
9-14\end{array}$ & - & - & $\begin{array}{c}\text { day } \\
9-14\end{array}$ & - & - & $\begin{array}{c}\text { day } \\
16-21\end{array}$ \\
\hline Sacrifice & & day 8 & day 8 & day 8 & day 15 & day 15 & day 15 & day 15 & day 15 & day 15 & day 22 & day 22 & day 22 \\
\hline
\end{tabular}

$\mathrm{AB}=$ antibiotic, $\mathrm{CD}=$ C. difficile, $\mathrm{PB}=$ probiotic, $\mathrm{EGF}=$ epidermal growth factor, $\mathrm{CY}=$ cyclosporine, $\mathrm{PPI}=$ proton pump inhibitor.

for two weeks before $C$. difficile inoculation to animals in Group 5 (5a, 5b and 5c). Standard strain of L. acidophilus (LA-5) (LactoBacil capsule, Organon India Limited, Gurgaon, India) at a dose of $10^{6} \mathrm{CFU} / \mathrm{ml}$ inoculum was administered daily for one week post $C$. difficile inoculation to the animals in subgroups $2 \mathrm{~b}, 3 \mathrm{~b}, 4 \mathrm{~b}$ and $5 \mathrm{~b}$. EGF (Sigma, USA) was administered daily at a dose of $100 \mu \mathrm{g} / \mathrm{kg}$ body weight to animals in subgroups 2c, 3c, 4c and 5c for one week post C. difficile inoculation [10].

\subsection{Sacrifice of Animals and Processing of Colonic Segments}

The animals in each group were sacrificed one week post $C$. difficile inoculation. The animals in control group (Group1) were sacrificed along with animals in Group 2. The colon was washed with sterile physiological saline to clear out the fecal material adhering to the mucosa. Two centimeters of the central portion of the colon was transferred to a vial containing $10 \mathrm{mM}$ proteolysis inhibitor containing ectoin and hydroxyectoin (HiMedia, Mumbai) and stored at $-20^{\circ} \mathrm{C}$ till the time of processing. For study of the tight junction proteins, the colonic segment was thawed and a cut was made transversally to expose the mucosa. The mucosa was scraped with a sterile surgical blade and homogenized in a glass homogenizer. The homogenate was then sonicated on ice for 30 seconds with $10 \mathrm{sec}$ intervals in between. The homogenate was vortexed vigorously in lysis buffer and was pipetted up and down to lyse the epithelial cells and to release the cellular proteins. The cell lysate was then centrifuged at $4472 \mathrm{~g}$ at $4^{\circ} \mathrm{C}$ and the supernatant was transferred to a fresh vial.

\subsection{Detection of Tight Junction Proteins}

The tight junction proteins viz. occludin, $\alpha$-actinin and zonula occludens (ZO-1) in the epithelial membrane of the colon of various animals were detected by western blotting methods [11] [12] with some modifications.

\subsubsection{Sodium Dodecyl Sulfate-Polyacrylamide Gel Electrophoresis}

The proteins from the cell lysates were separated by SDS-PAGE (Figure 1) using the Mini-PROTEAN 3 system (Bio-Rad, USA). Discontinuous polyacrylamide gels consisting of resolving gel (8\%) and stacking gel (4\%) were prepared for electrophoresis. The comb was inserted immediately and the stacking gel was allowed to polymerize for $45 \mathrm{~min}$. Then the comb was gently removed and the wells were rinsed thoroughly with running buffer. The gel plates were placed in the electrode assembly. The samples were diluted in sample buffer (2:1) and heated at $95^{\circ} \mathrm{C}$ for $5 \mathrm{~min}$. and then immediately placed on an ice bath. Samples were loaded into the wells of the gel along with a protein containing molecular weights varying from 29,000 Da to 205,000 Da (Bangalore 


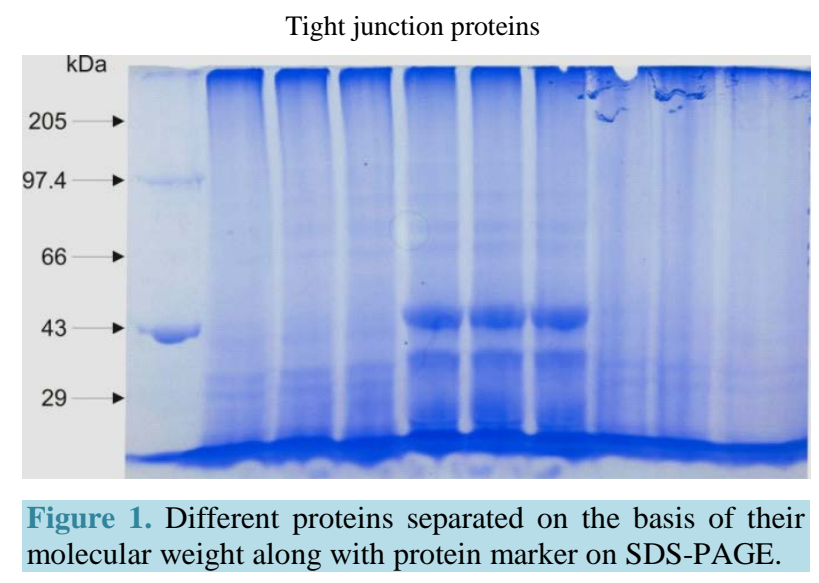

Genie, Bengaluru) as the molecular weight marker of proteins. Running buffer was added to the inner and outer chambers of Mini-Tank and the gel was run at 150 volts constant for $45 \mathrm{~min}$ and the gel was removed gently from the Gel Cassette Sandwich.

\subsubsection{Western Blotting}

Western blotting for tight junction proteins was done using semi-dry electrophoretic blotting system (CBS Scientific Company, Inc, USA). Blotting was accomplished by layering transfer membrane and gel between buffer saturated blotting paper, minimizing the amount of buffer required. Eight pieces of Whatman filter paper No. 1 were cut exactly to the size of the gel, and soaked in transfer buffer [13] until saturated. The membrane (PVDF, Millipore) was hydrated by first floating in a tray of de-ionized water followed by 5 min of total immersion.

The gel plate sandwich after SDS-PAGE electrophoresis was soaked briefly in a tray of de-ionized water. Stacking gel was removed with a spatula and discarded. The Mylar mask was inserted over the bottom platinum coated titanium electrode which was the anode fixed in place, whereas the cathode was adjustable and lying within the lid of the apparatus. Four pieces of saturated filter paper were carefully centered over the cutout in the Mylar mask. The filter papers were flattened over the surface. The saturated membrane was applied on the top of the paper and the gel was placed on the membrane. The remaining four sheets of filter paper were stacked on the top of the gel. The lid which contained the cathode was closed. Then the power supply was applied and the blot was run for one hour with a constant current of $40 \mathrm{~mA}$. After transfer of the proteins, the membrane was removed and placed in blocking buffer containing 5\% skimmed milk, and incubated at room temperature overnight.

\subsubsection{Immunostaining for the Detection of Tight Junction Proteins}

After the blotting step, the membrane was immunostained for the detection of three proteins involved in tight junctions i.e. occludin, $\alpha$-actinin and ZO-1 separately [12]. The membrane was washed thrice for 5 mins each with agitation using washing buffer at room temperature. After this the membrane was kept in $10 \mathrm{ml}$ of 1 in 1000 diluted anti-occludin (BD Biosciences, USA) for $4 \mathrm{~h}$ at room temperature with gentle shaking. The membrane was then washed thrice for 5 mins each with agitation using washing buffer at room temperature. Then the membrane was placed in $10 \mathrm{ml}$ of 1 in 1000 diluted horseradish peroxidase labeled anti-mouse IgG in phosphate buffered saline (PBS) pH 7.2 at room temperature for 2 h with gentle agitation. The membrane was again washed thrice for 10 min each in washing buffer. Then the membrane was washed once with PBS (pH 7.2) and placed in $10 \mathrm{ml}$ of color development solution comprising of 3,3-diaminobenzidinetetrahydrochloride and hydrogen peroxide and was gently agitated until the bands appeared. The reaction was stopped with distilled water. The membrane was similarly immunostained using anti- $\alpha$-actinin (Sigma, USA) and anti-zonula occludens (BD Biosciences, USA) and analyzed qualitatively for the presence of the tight junction proteins.

\subsection{Statistical Analysis}

Data was analyzed using the SPSS version 10 software program. Analysis of Variance test was applied for ana- 
lyzing significant differences. Dunnett t-test was applied to compare all the groups against the control. StudentNewman-Keuls test was applied for inter-group comparisons between the groups. A probability value of $\mathrm{P}<$ 0.05 was considered to indicate significant differences.

\section{Results}

The three tight junction proteins (occludin, $\alpha$-actinin and ZO-1) were present in $100 \%$ each of the animals belonging to Group 1 and Group 2 (subgroups 2a, 2b and 2c). The percentage presence of the three proteins and the statistical comparison between the various subgroups is given in Table 2 and Table 3 respectively.

In Group 3, of the three proteins studied, occludin was found in 50\% and $\alpha$-actinin in 33.3\% of the animals receiving ampicillin and C. difficile (subgroup 3a). However, ZO-1 was not detected in any of these animals. In animals receiving $L$. acidophilus after ampicillin and $C$. difficile inoculation (subgroup $3 b$ ), occludin was detected in $83.3 \%$ and $\alpha$-actinin in 33.3\% of them whereas ZO- 1 was not detected in any animal of this subgroup.

Table 2. Tight junction proteins in different groups.

\begin{tabular}{|c|c|c|c|c|c|}
\hline Groups & & Subgroups & Occludin (\%) & $\alpha$-actinin (\%) & Zonula-occludens (\%) \\
\hline \multirow[t]{2}{*}{1} & & & 100 & 100 & 100 \\
\hline & $2 \mathrm{a}$ & (CD) & 100 & 100 & 100 \\
\hline \multirow[t]{3}{*}{2} & $2 b$ & $(\mathrm{CD}+\mathrm{PB})$ & 100 & 100 & 100 \\
\hline & 2c & $(\mathrm{CD}+\mathrm{EGF})$ & 100 & 100 & 100 \\
\hline & За & $(\mathrm{AB}+\mathrm{CD})$ & 50 & 33.3 & 0 \\
\hline \multirow[t]{3}{*}{3} & $3 b$ & $(\mathrm{AB}+\mathrm{CD}+\mathrm{PB})$ & 83.3 & 33.3 & 0 \\
\hline & 3c & $(\mathrm{AB}+\mathrm{CD}+\mathrm{EGF})$ & 100 & 66.7 & 16.7 \\
\hline & $4 a$ & $(\mathrm{CY}+\mathrm{CD})$ & 16.7 & 50 & 50 \\
\hline \multirow[t]{3}{*}{4} & $4 \mathrm{~b}$ & $(\mathrm{CY}+\mathrm{CD}+\mathrm{PB})$ & 66.7 & 100 & 66.7 \\
\hline & $4 \mathrm{c}$ & $(C Y+C D+E G F)$ & 33.3 & 66.7 & 100 \\
\hline & $5 a$ & $(\mathrm{PPI}+\mathrm{CD})$ & 0 & 16.7 & 0 \\
\hline \multirow[t]{2}{*}{5} & $5 b$ & $(\mathrm{PPI}+\mathrm{CD}+\mathrm{PB})$ & 50 & 33.3 & 16.7 \\
\hline & $5 c$ & $(\mathrm{PPI}+\mathrm{CD}+\mathrm{EGF})$ & 100 & 33.3 & 16.7 \\
\hline
\end{tabular}

$\mathrm{CD}=$ C. difficile, $\mathrm{PB}=$ Probiotic, $\mathrm{EGF}=$ epidermal growth factor, $\mathrm{AB}=$ antibiotic, $\mathrm{CY}=$ cyclosporine, $\mathrm{PPI}=$ proton pump inhibitor, $\%=$ Percentage of animals with TJP proteins.

Table 3. Statistical comparison of tight junction proteins between various sub-groups.

\begin{tabular}{cccc}
\hline Subgroups & $\begin{array}{c}\text { Occludin } \\
\text { (P value) }\end{array}$ & $\begin{array}{c}\alpha \text {-actinin } \\
\text { (P value) }\end{array}$ & $\begin{array}{c}\text { Zonula-occludens } \\
\text { (P value) }\end{array}$ \\
\hline Control (1) vs AB + CD (3a) & 0.091 & $0.030^{*}$ & $0.001^{*}$ \\
AB + CD (3a) vs AB + CD + PB (3b) & 0.273 & 0.727 & 1.7 \\
AB + CD (3a) vs AB + CD + EGF (3c) & 0.091 & 0.284 & 0.500 \\
Control (1) vs CY + CD (4a) & $0.008^{*}$ & 0.091 & 0.091 \\
CY + CD (4a) vs CY + CD + PB (4b) & 0.121 & 0.091 & 0.500 \\
CY + CD (4a) vs CY + CD + EGF (4c) & 0.500 & 0.0500 & 0.091 \\
Control (1) vs PPI + CD (5a) & $0.001^{*}$ & $0.030^{*}$ & $0.001^{*}$ \\
PPI + CD (5a) vs PPI + CD + PB (5b) & 0.091 & 0.500 & 0.500 \\
PPI + CD (5a) vs PPI + CD + EGF (5c) & $0.001^{*}$ & 0.227 & 0.500 \\
\hline
\end{tabular}

$\mathrm{CD}=$ C. difficile, $\mathrm{PB}=$ Probiotic, $\mathrm{EGF}=$ epidermal growth factor, $\mathrm{AB}=$ antibiotic, $\mathrm{CY}=$ cyclosporine, $\mathrm{PPI}=$ proton pump inhibitor, ${ }^{*} \mathrm{P}<0.05$ significant. 
In subgroup 3c (ampicillin, C. difficile and EGF) occludin was detected in $100 \%$ of the animals, $\alpha$-actinin in $66.7 \%$ and ZO-1 (Figure 2) in 16.7\% of the animals (Figure 3). In subgroup 3a where the animals received $C$. difficile after challenge with ampicillin, $\alpha$-actinin and ZO-1 were present in significantly less $(\mathrm{P}<0.05)$ numbers of animals. The same was also observed for occludin although the decrease was statistically insignificant $(\mathrm{P}=$ 0.091) when compared with controls. Occludin and $\alpha$-actinin was found in apparently more numbers in $L$. acidophilus receiving animals although statistically insignificant when compared to animals not receiving the probiotic after ampicillin and $C$. difficile administration. Similarly in EGF receiving animals, the three proteins were found in apparently more number of animals although statistically insignificant $(P>0.05)$ when compared with subgroup 3a.

In Group 4, occludin was detected in $16.7 \%$ and $\alpha$-actinin and ZO-1 in 50\% of animals given cyclosporine and C. difficile (subgroup 4a). In animals receiving probiotic after cyclosporine and C. difficile inoculation (subgroup $4 \mathrm{~b}$ ), occludin was detected in $66.7 \%, \alpha$-actinin in $100 \%$ and ZO-1 in $66.7 \%$ of the animals. In subgroup $4 \mathrm{c}$ (cyclosporine, C. difficile and EGF) occludin and ZO-1 were detected in $100 \%$ and $\alpha$-actinin in $33.3 \%$ of the animals (Figure 4). All the three proteins were present in apparently less number of animals receiving cyclosporine and $C$. difficile (subgroup 4a). However, the decrease was significant only for occludin $(\mathrm{P}<0.05)$. The three proteins were detected in apparently more numbers in the two biotherapeutics receiving animals i.e. (4b and $4 \mathrm{c}$ ), however the increase was not statistically significant $(\mathrm{P}>0.05)$.

In Group 5, occludin and ZO-1 were not detected in any of the animals given lansoprazole and C. difficile (subgroup 5a). However $\alpha$-actinin was found in $16.7 \%$ of the animals. In animals receiving L. acidophilus after lansoprazole and C. difficile administration (subgroup 5b), occludin was detected in 50\%, $\alpha$-actinin in 33.3\% and ZO-1 in $16.7 \%$ of the animals. In subgroup 5c (lansoprazole, $C$. difficile and EGF) occludin was detected in $100 \%$, $\alpha$-actinin in $33.3 \%$ and $\mathrm{ZO}-1$ in $66.7 \%$ of the animals (Figure 5). The three proteins were present in

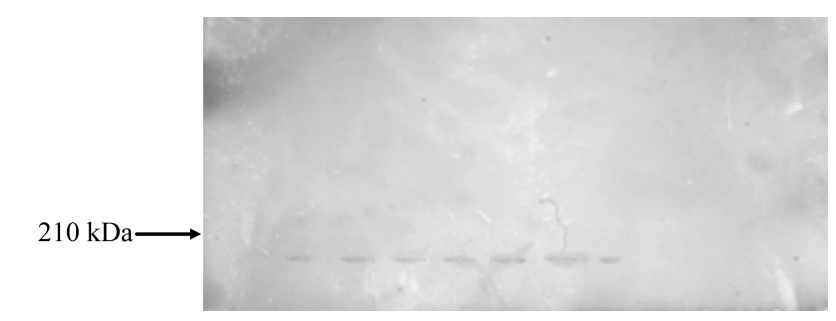

Figure 2. PVDF membrane immunostained using anti-ZO-1 representing the presence of Zona occludens.

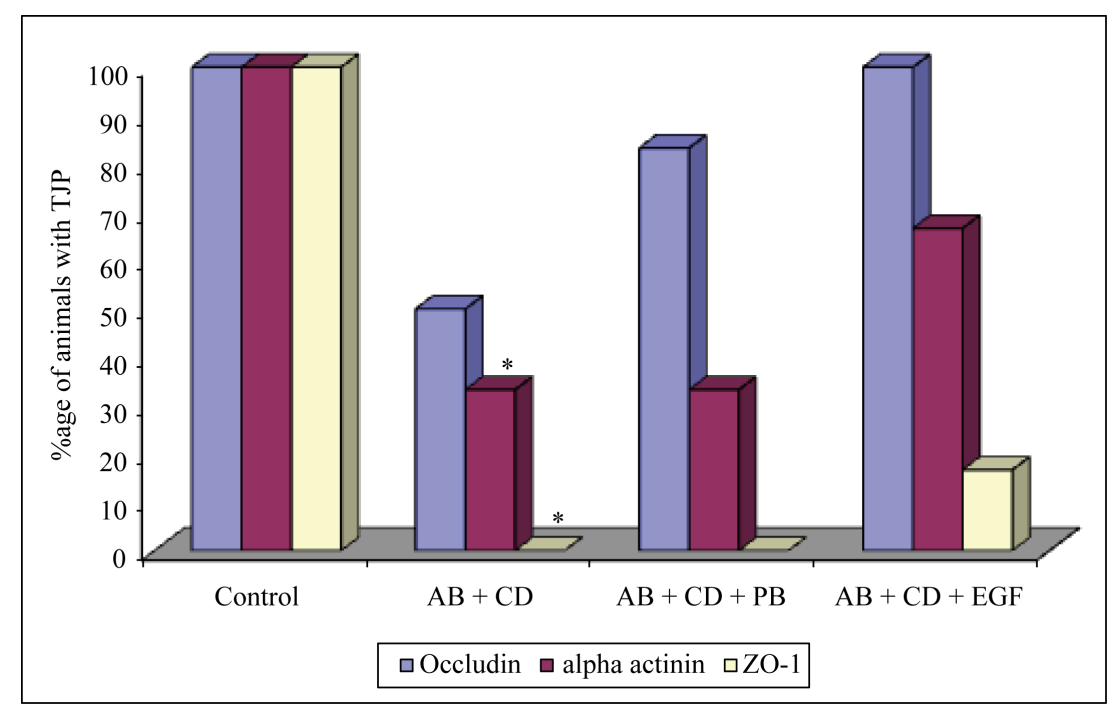

Figure 3. Presence of tight junction proteins in Group 1 and Group 3. AB = antibiotic, $\mathrm{CD}=$ C. difficile, $\mathrm{PB}=$ probiotic, $\mathrm{EGF}=$ epidermal growth factor, $\mathrm{ZO}-1=$ zonula occludens, TJP $=$ tight junction proteins ${ }^{*} \mathrm{P}<0.05$ (Control vs $\left.\mathrm{AB}+\mathrm{CD}\right)$. 


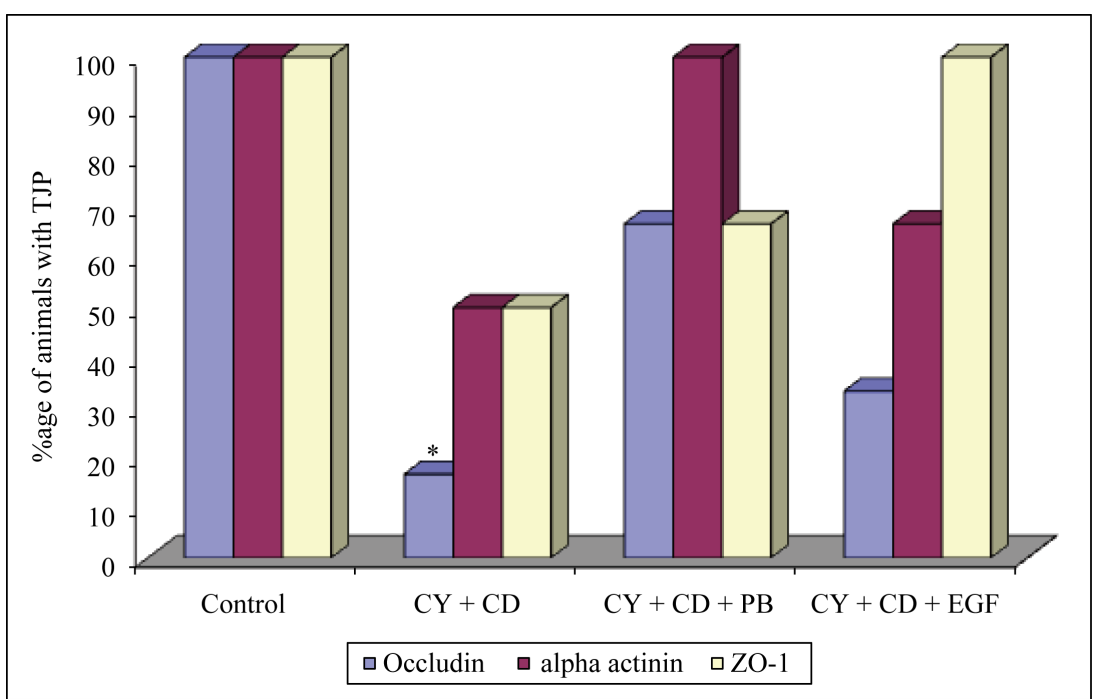

Figure 4. Presence of tight junction proteins in Group 1 and Group 4. CY = cyclosporine, $\mathrm{CD}=\mathrm{C}$. difficile, $\mathrm{PB}=$ probiotic, $\mathrm{EGF}=$ epidermal growth factor, $\mathrm{ZO}-1=$ zonula occludens, TJP = tight junction proteins, ${ }^{*} \mathrm{P}<0.05$ (Control vs CY + CD).

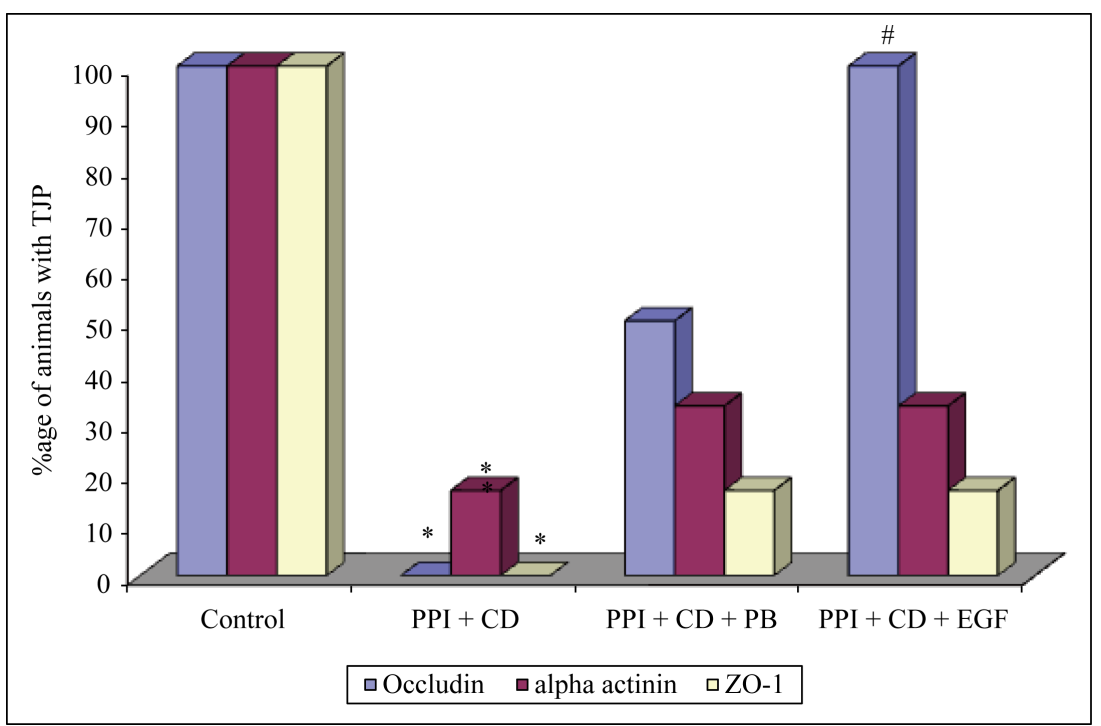

Figure 5. Presence of tight junction proteins in Group 1 and Group 5. PPI = proton pump inhibitor, $\mathrm{CD}=C$. difficile, $\mathrm{PB}=$ probiotic, $\mathrm{EGF}=$ epidermal growth factor, ZO-1 = zonula occludens, ${ }^{*} \mathrm{P}<0.05$ (Control vs PPI $\left.+\mathrm{CD}\right),{ }^{\#} \mathrm{P}<0.05$ (PPI $+\mathrm{CD}$ vs PPI + CD + EGF).

significantly less $(\mathrm{P}<0.05)$ number of animals receiving lansoprazole and $C$. difficile when compared to controls. In inter-subgroup comparison, the three proteins were present in apparently more numbers in the $L$. acidophilus receiving (subgroup 5b) and EGF receiving (subgroup 5c) animals; however the increase was significant only for occludin in EGF receiving animals (subgroup 5c).

\section{Discussion}

C. difficile toxins influence barrier function in the intestinal epithelial cells [7]. In the present study, occludin and $\alpha$-actinin were present in significantly less number of animals receiving ampicillin before $C$. difficile challenge, compared to controls, though ZO-1 was not found in them even after the administration of L. acidophilus. The three proteins were present in $100 \%$ of the animals receiving only $C$. difficile challenge. Nusrat and co- 
workers [11] studied the effect of $C$. difficile toxins on the tight junction organization and found decreased association of ZO-1 with the actin cytoskeleton after exposure to C. difficile toxin A and B. Such changes were accompanied by a diminished pool of high-molecular weight occludin.

Similarly, in the present study, tight junction proteins were also present in less number of animals receiving cyclosporine or lansoprazole. C. difficile toxin A and B mediate their effects on tight junction structure and function via inactivation of Rho proteins [11], which probably resulted in the absence of these proteins in the drug-treated animals. It is likely that the toxins produced by the colonized $C$. difficile resulted in disruption of the extracellular matrix and led to decrease of tight junction proteins.

The pathogenic process of CDAD begins with the binding of toxin A to receptors on the mucosal side of intestinal cells. Mediators released on the basolateral side of the epithelium activate the tissue macrophages to produce proinflammatory cytokines. These events lead to an opening of the tight junctions, a strong inflammatory cell infiltration in the epithelium, and later on a mucosal injury. In the clinical situation, toxin B when present, also moves across the epithelium via opened tight junctions, reaching the basolateral cell surfaces, strongly aggravating the mucosal necrosis and inflammation. Thus when immune cells are destroyed, gross pathological changes are induced [14].

L. acidophilus is the most commonly used probiotic for the treatment of gastrointestinal diseases. It is believed that $L$. acidophilus adheres to the mucosal surfaces to provide an active bacterial biofilm that exerts a "barrier effect" as well as produces antimicrobial components against the pathogens [15]. On a general assessment most of the animals in all the subgroups administered L. acidophilus in the present study showed considerable presence of the tight junction proteins. On analysis of individual subgroups, occludin and $\alpha$-actinin were present in more number of animals in the probiotic receiving animals even after antibiotic administration; however ZO-1 was not found in any of the animals. Similarly in the animals receiving probiotic in addition to cyclosporine or PPI groups, all the three proteins (occludin, $\alpha$-actinin and ZO-1) were found in more number of animals when compared with their respective subgroups not receiving L. acidophilus. C. difficile toxin mediated damage is accompanied by a reduction in transepithelial resistance [16] and epithelial barrier integrity [17]. $L$. acidophilus and Streptococcus thermophilus have shown to have beneficial effect on barrier function in cell lines in vivo [12].

Lactobacilli adhering to the mucosal surfaces inhibit the attachment of pathogenic bacteria and enhance mucin secretion [18] thereby improving mucosal barrier function and decreasing permeability to macromolecules and toxins [19]. In an earlier report also it was observed that Lactobacillus decreased the permeability of mannitol in rat colon colonized by Escherichia coli, Klebsiella pneumoniae, and Streptococcus viridians [19]. The same kind of barrier effect may be applicable to the animals in the present study, where L. acidophilus administration resulted in the maintenance of integrity of the epithelial membrane as seen by the normal presence of tight junction proteins in more number of animals.

EGF plays an important role in the regulation of cell growth, proliferation and differentiation [20] and promotes epithelial proliferation in adult gut [21]. The potential value of using EGF as a therapeutic tool to treat gastrointestinal injury has been raised previously by some investigators [10] [22]. Increased presence of the three proteins studied was found in the colonic segment of animals given EGF in all the groups given ampicillin, cyclosporine or PPI. It has been reported that EGF prevented C. difficile toxin inducing disruption of cytoskeletal F-actin [8]. A growing body of evidence indicates that EGF is capable of modulating actin assembly [23]-[25]. EGF was demonstrated to stimulate F-actin polymerization during stress fiber formation and focal adhesion assembly when added to fibroblasts in vitro [23]. This effect could be blocked by Clostridium botulinum exoenzyme C3-induced ADP-ribosylation of Rho, which is known to inactivate Rho, thus indicating that EGF mediated its effect via activation of Rho [23]. Furthermore, the EGF receptor was demonstrated to directly bind the actin cytoskeleton [26].

Several intracellular targets are suggested to enable EGF to inhibit toxin-induced disorganization of the cytoskeleton. The mechanisms hypothesized are that EGF could activate Rho, prevent toxin-induced inactivation of Rho and stimulate actin polymerization via Rho or by direct binding of the activated EGF receptor to F-actin, thereby resulting in stabilization of the cytoskeleton [24] [27]-[29]. Thus, EGF probably stabilizes the actin cytoskeleton by enabling epithelial cells to withstand the cytotoxic action of C. difficile toxins A and B.

All the tight junction proteins studied were found in the colonic segment of more number of animals receiving L. acidophilus or EGF in antibiotic, cyclosporine and PPI administered groups, suggesting the role of biotherapeutics in protecting barrier function of the intestinal mucosa. Both L. acidophilus and EGF helped in the pro- 
tection of tight junction barrier by normalizing the proteins in the colonic segments. Thus administration of biotherapeutics like probiotic and EGF helped in the reduction of severity of CDAD in animals. The limitation of the present study was that only qualitative detection of tight junction proteins was done. Further research is required on the quantitative estimation of these important barrier proteins.

\section{Acknowledgements}

We are indebted to Dr. M. Delmee, Belgium, for the standard C. difficile strain and Mr. R.C. Goel, for statistical evaluation of the data.

\section{Funding}

The study was carried out by the internal grants of the Institute. Dr. Sukhminderjit Kaur received the Senior Research Fellowship from the Indian Council of Medical Research, New Delhi, India.

\section{Transparency Declaration}

No conflict of interest.

\section{References}

[1] Hossain, M., Crook, T.J. and Keoghane, S.R. (2008) Clostridium difficile in Urology. Annals of the Royal College of Surgeons of England, 90, 36-39. http://dx.doi.org/10.1308/003588408X242358

[2] Tsutsumi, L.S., Owusu, Y.B., Hurdlre, J.G. and Sun, D. (2014) Progress in the Discovery of Treatment for C. difficile infection. A Clinical and Medicinal Chemistry Review. Current Topics in Medicinal Chemistry, 14, 152-175. http://dx.doi.org/10.2174/1568026613666131113154753

[3] Lemeni, D. (2010) Nosocomial Clostridium Difficile Diarrhea-Adverse Effect of Antibiotic Therapy. Bacteriol Virusol Parazitol Epidemiol, 55, 141-144.

[4] Crogan, N.L. and Evans, B.C. (2007) Clostridium difficile: An Emerging Epidemic in Nursing Homes. Geriatric Nursing, 28, 161-164. http://dx.doi.org/10.1016/j.gerinurse.2007.04.005

[5] Vaishnavi, C. (2009) Established and Potential Risk Factors for Clostridium difficile Infection. Indian Journal of Medical Microbiology, 27, 291-302.

[6] Ulliuwishewa, D., Anderson, R.C., McNabb, W.C., Moughan, P.J., Wells, J.M. and Roy, N.C. (2011) Regulation of Tight Junction Permeability by Intestinal Bacteria and Dietary Components. Journal of Nutrition, 41, 769-776. http://dx.doi.org/10.3945/jn.110.135657

[7] Aktories, K. (1997) Bacterial Toxins that Target Rho Proteins. Journal of Clinical Investigation, 99, 827-829. http://dx.doi.org/10.1172/JCI119245

[8] Riegler, M., Sedivy, R., Sogukoglu, T., Castagliuolo, I., Pothoulakis, C., Cosentini, E., Bischof, G., Hamilton, G., Teleky, B., Feil, W., et al. (1997) Epidermal Growth Factor Attenuates Clostridium difficile Toxin A- and B-Induced Damage of Human Colonic Mucosa. American Journal of Physiology, 273, G1014-G1022.

[9] Kaur, S., Vaishnavi, C., Kochhar, R., Prasad, K.K. and Ray, P. (2012) Effect of Biotherapeutics on Antitoxin IgG in Experimentally Induced Clostridium difficile Infection. Indian Journal of Medical Microbiology, 30, 31-36.

[10] Buret A., Oslon, M.E., Gall, D.J. and Hardin, J.A. (1998) Effects of Orally Administered Epidermal Growth Factor on Enteropathogenic Escherichia coli Infection in Rabbits. Infection and Immunity, 66, 4917-4923.

[11] Nusrat, A., Eichel-Streiber, C., Turner, J.R., Verkade, P., Madara, J.L. and Parkos, C.A. (2001) Clostridium difficile toxins Disrupt Epithelial Barrier Function by Altering Membrane Microdomain Localization of Tight Junction Proteins. Infection and Immunity, 69, 1329-1336. http://dx.doi.org/10.1128/IAI.69.3.1329-1336.2001

[12] Resta-Lenert, R. and Barret, K.E. (2003) Live Probiotics Protect Intestinal Epithelial Cells from the Effects of Infection with Enteroinvasive Escherichia coli (EIEC). Gut, 52, 988-997. http://dx.doi.org/10.1136/gut.52.7.988

[13] Towbin, J., Staehelin, T. and Gordon, J. (1979) Electrophoresis Transfer of Protein from Polyacrylamide Gels to Nitrocellulose Sheets: Procedure and Some Applications. Proceedings of the National Academy of Sciences of the United States of America, 76, 4350- 4354. http://dx.doi.org/10.1073/pnas.76.9.4350

[14] Thalestam, M. and Chaves-Olarte, E. (2000) Cytotoxic Effects of the Clostridium difficile Toxins. Current Topics in Microbiology and Immunology, 250, 85-96. http://dx.doi.org/10.1007/978-3-662-06272-2 4

[15] Yang, K.M., Jiang, Z.Y., Zheng, C.T., Wang, L. and Yang, X.F. (2014) Effect of Lactobacillus plantarum on Diarrhea 
and Intestinal Barrier Function of Young Piglets Challenged with Enterotoxigenic Escherichia coli K88. Journal of Animal Science, 92, 1496-1503. http://dx.doi.org/10.2527/jas.2013-6619

[16] Miura, M., Kato, H. and Matsushita, O. (2011) Identification of a Novel Virulence Factor in Clostridium difficile That Modulates Toxin Sensitivity of Cultured Epithelial Cells. Infection and Immunity, 79, 3810-3820. http://dx.doi.org/10.1128/IAI.00051-11

[17] Castagluiolo, I., Riegler, M.F., Valenick, L., LaMont, J.T. and Pothoulakis, C. (1999) Saccharomyces boulardii Protease Inhibits the Effects of Clostridium difficile Toxins A and B in Human Colonic Mucosa. Infection and Immunity, 67, 302-307.

[18] Mack, D.R., Ahrne, S., Hyde, L., Wei, S. and Hollingsworth, M.A. (2003) Extracellular MUC3 Mucin Secretion Follows Adherence of Lactobacillus Strains to Intestinal Epithelial Cells in Vitro. Gut, 52, 827-833.

[19] García-Lafuente, A., Antolin, M., Guarner, F., Crespo, E. and Malagelada, J.R. (2001) Modulation of Colonic Barrier Function by the Composition of the Commensal Flora in the Rat. Gut, 48, 503-507. http://dx.doi.org/10.1136/gut.48.4.503

[20] Hanley, S.C., Assouline-Thomas, B., Makhlin, J. and Rosenberg, L. (2011) Epidermal Growth Factor Induces Adult Human Islet Cell Dedifferentiation. Journal of Endocrinology, 211, 231-239. http://dx.doi.org/10.1530/JOE-11-0213

[21] Gospodarowicz, D. (1981) Epidermal and Nerve Growth Factor in Mammalian Development. Annual Review of Physiology, 43, 251-263. http://dx.doi.org/10.1146/annurev.ph.43.030181.001343

[22] Procaccino, F., Reinshagen, M., Hoffmann, P., Zeeh, J.M., Lakshmanan, J., McRoberts, J.A., Patel, A., French, S. and Eysselein, V.E. (1994) Protective Effect of Epidermal Growth Factor in an Experimental Model of Colitis in Rats. Gastroenterology, 107, 12-17.

[23] Banan, A., Zhang, Y., Losurdo, J. and Keshavarzian, A. (2000) Carbonylation and Disassembly of the F-Actin Cytoskeleton in Oxidant Induced Barrier Dysfunction and Its Prevention by Epidermal Growth Factor and Transforming Growth Factor $\alpha$ in a Human Colonic Cell Line. Gut, 46, 830-837. http://dx.doi.org/10.1136/gut.46.6.830

[24] Nobes, C.D., Hawkins, P., Stephens, L. and Hall, A. (1995) Activation of the Small GTP-Binding Proteins rho and rac by Growth Factor Receptors. Journal of Cell Science, 108, 225-233.

[25] Craig, W.S. and Johnson, R.P. (1996) Assembly of Focal Adhesions: Progress, Paradigms, and Portents. Current Opinion in Cell Biology, 8, 74-85. http://dx.doi.org/10.1016/S0955-0674(96)80051-2

[26] Henegouwen, P.M.V.B.E., den Hartigh, J.C., Romeyn, P., Verkleij, A.J. and Boonstra, J. (1992) The Epidermal Growth Factor Receptor Is Associated with Actin Filaments. Experimental Cell Research, 199, 90-97. http://dx.doi.org/10.1016/0014-4827(92)90465-K

[27] den Hartigh, J.C., Henegouwen, P.M.V.B.E., Verkleij, A.J. and Boonstra, J. (1992) The EGF Receptor Is an Actin-Binding Protein. The Journal of Cell Biology, 2, 349-355. http://dx.doi.org/10.1083/jcb.119.2.349

[28] Hotchin, N.A. and Hall, A. (1995) The Assembly of Integrin Adhesion Complexes Require Both Extracellular Matrix and Intracellular rho/rac GTPases. The Journal of Cell Biology, 131, 1857-1865. http://dx.doi.org/10.1083/jcb.131.6.1857

[29] Parsons, J.T. (1996) Integrin-Mediated Signaling: Regulation by Tyrosine Kinases and Small GTP-Binding Proteins. Current Opinion in Cell Biology, 8, 148-152. http://dx.doi.org/10.1016/S0955-0674(96)80059-7 


\section{List of Abbreviations}

- $\%=$ Percentage

- $\mathrm{AB}=$ antibiotic

- $\mathrm{ADP}=$ Adenosine di-phosphate.

- $\mathrm{CD}=$ C. difficile

- $\mathrm{CDAD}=$ Clostridium difficile associated disease

- $\mathrm{CY}=$ cyclosporine

- $\mathrm{EGF}=$ Epidermal growth factor

- L. acidophilus = Lactobacillus acidophilus

- $\mathrm{PB}=$ Probiotic

- PBS = Phosphate buffered saline

- $\quad$ PPI = Proton pump inhibitor

- $\quad$ PVDF = Polyvinylidene difluoride

- SDS-PAGE = Sodium dodecyl sulfate-polyacrylamide gel electrophoresis

- $\quad$ TJP = tight junction proteins

- $\mathrm{ZO}-1=$ zonula occludens 